\title{
Empiema subdural espinal como causa poco común de síndrome medular: reporte de caso
}

Subdural spinal empyema as a unusual cause of spinal syndrome: a case report

\author{
Jorge A. Contreras-Jaquez*, Fátima Peña-Muñoz, Isaac G. Morales-Villaseñor y Julisa Hernández-Chávez \\ Departamento de Admisión Médica Continua-Urgencias, Unidad Médica de Alta Especialidad, Hospital de Especialidades, Centro Médico Nacional \\ de Occidente, Instituto Mexicano del Seguro Social (IMSS), Guadalajara, Jalisco, México
}

\section{Introducción}

El absceso epidural es una infección supurativa rara, pero importante, del sistema nervioso central, localizada dentro del espacio epidural espinal ${ }^{1}$, con una incidencia de $1 / 10.000^{1}$, regularmente asociada a Staphylococcus aureus, que requiere una pronta identificación y la instauración de tratamiento para prevenir secuelas neurológicas graves o la muerte. El diagnóstico oportuno y el tratamiento adecuado pueden evitar complicaciones y lograr la curación en muchos casos. Tanto el diagnóstico como el tratamiento del absceso epidural, que a menudo incluye un procedimiento quirúrgico para la aspiración o el drenaje del absceso, se han beneficiado del advenimiento de las técnicas de imagen modernas, como la tomografía computarizada y especialmente la resonancia magnética ${ }^{1-3}$.

\section{Presentación del caso}

Varón de 51 años, de oficio mecánico, consumo de alcohol positivo, suspendido en los 3 meses previos, desde hace 10 años a razón de cuatro cervezas diarias. Diagnóstico de diabetes mellitus con mal control nutricional y farmacológico, refiere consumo de metformina, $850 \mathrm{mg}$, tabletas, cada 24 horas, con mal apego.

Inicia su padecimiento 2 semanas antes de su ingreso con astenia y adinamia, y 1 semana previa se agrega limitación de las actividades cotidianas, con dolor en la región interescapular, de carácter punzante, transfictivo, constante, de gran intensidad, y disminución de fuerza en las extremidades inferiores, con necesidad de apoyo bilateral para la marcha, con preservación de la sensibilidad y control de esfínteres. Dicho cuadro progresó a paraparesia de miembros pélvicos, motivo por el cual 1 semana previa fue llevado a un hospital de segundo nivel donde presentó pérdida del control de esfínteres, ameritando colocación de sonda vesical. Así mismo, requirió apoyo con oxígeno suplementario por desaturación reportada hasta el $83 \%$. Durante su estancia en el hospital presenta descontrol glucémico, con cifras de $500 \mathrm{mg} / \mathrm{dl}$, así como datos de proceso infeccioso, adjudicando síntomas de infección de vías urinarias y neumonía adquirida en la comunidad. Fue manejado con antimicrobiano y se otorgó un ciclo con esteroides (1.5 g), sin mostrar mejoría de su padecimiento. Durante la hospitalización, la debilidad se acrecienta y por ello es derivado a una unidad de alta especialidad para su valoración.

\section{Correspondencia:}

*Jorge A. Contreras-Jaquez

E-mail: urgenciologo.contreras@gmail.com
Disponible en internet: 07-03-2022

Fecha de recepción: 08-12-2021

Fecha de aceptación: 13-12-2021 DOI: 10.24875/REIE.21000287
Rev Educ Investig Emer. 2022;4(Supl 1):78-81 www.medicinadeemergencias.com bajo la licencia CC BY-NC-ND (http://creativecommons.org/licenses/by-nc-nd/4.0/). 


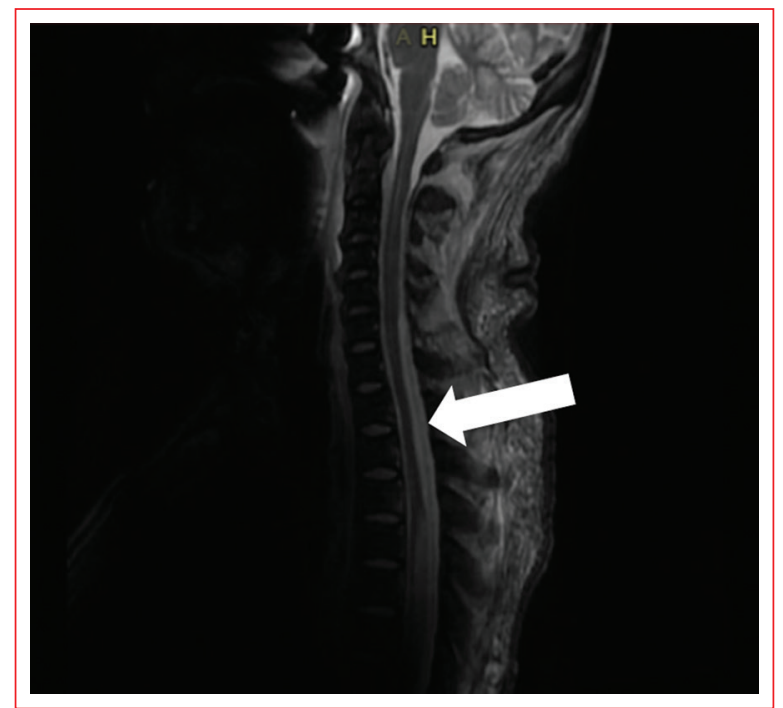

Figura 1. Resonancia magnética: imagen hiperintensa en T2.

A su ingreso muestra malas condiciones generales, palidez de piel y tegumentos, signos de sobrecarga de volumen a nivel periférico, dependiente de oxígeno con una saturación del $90 \%$, alerta, consciente, orientado, emite, repite y comprende, no apraxias, no agnosias, fondo de ojo con papila bien delimitada en ambos ojos, sin datos de lesiones agregadas. Pupilas simétricas, con fotomotor y consensual presente. Versiones, ducciones y vergencias sin alteraciones en ambos ojos. No alteración sensitiva en V1, V2 y V3 de manera bilateral. Gesticulación simétrica facial. Elevación simétrica del velo del paladar, reflejo nauseoso presente. Movimientos linguales preservados, respiración superficial, disminución de entrada de aire bilateral, con matidez a la percusión en relación con síndrome pleuropulmonar de derrame pleural. Tono de esfínter anal ausente. Tono y trofismo disminuidos de manera global. Fuerza 4/5 en ambas extremidades superiores de manera distal y $2 / 5$ en ambas extremidades superiores de manera proximal. Fuerza 0/5 en ambas extremidades inferiores. Reflejo de estiramiento muscular +/++++ en las extremidades superiores y $-/++++$ en las extremidades inferiores. Respuesta plantar indiferente bilateral. Nivel de anestesia por debajo de T5 de ambos lados, por arriba, exterocepción, palestesia y batiestesia preservadas.

Se realiza punción lumbar, obteniendo pobre flujo de líquido al tercer intento, de características hematopurulentas.

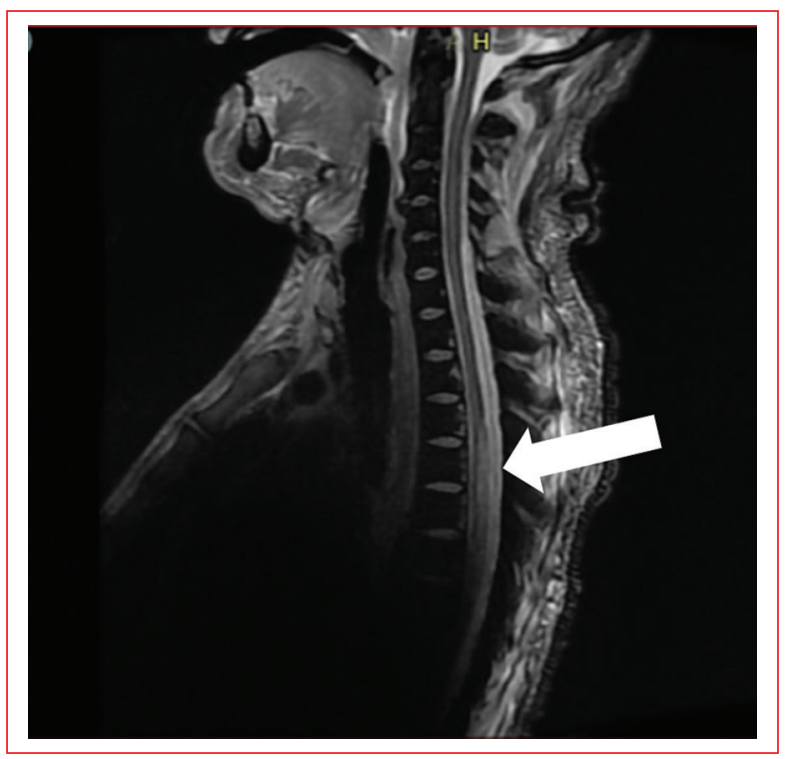

Figura 2. Resonancia magnética: imagen hiperintensa en T2 a nivel T4-T8.

\section{Estudios de laboratorio}

- Ingreso: hemoglobina $9.8 \mathrm{~g} / \mathrm{dl}$, leucocitos $8920 \mathrm{cel} /$ micolitro, neutrófilos $7480 \mathrm{cel} / \mathrm{micolitro,} \mathrm{glucosa}$ $226 \mathrm{mg} / \mathrm{dl}$, urea $17.98 \mathrm{mg} / \mathrm{dl}$, creatinina $0.26 \mathrm{mg} / \mathrm{dl}$.

- Citoquímico de líquido cefalorraquídeo: eritrocitos abundantes $100 \%$ normales, leucocitos 6400 (polimorfonucleares $90 \%$ y mononucleares $10 \%$ ), glucosa 76, proteínas 3933.

\section{Estudios de gabinete}

- Tomografía computarizada de envío: columna dorso-lumbar que reporta abombamiento difuso del disco en L5-S1, resto de niveles intervertebrales con densidad y aspecto conservados.

- Resonancia magnética: se observa imagen hiperintensa en T2 en el espacio subdural en T2-T6 (Figs. 1 y 2).

\section{Diagnósticos diferenciales}

Los diagnósticos diferenciales incluyen síndrome medular de etiología tumoral y mielitis transversa.

\section{Tratamiento}

Se inicia antibioticoterapia empírica con meropenem y vancomicina. Se solicita valoración al servicio de neurocirugía para drenaje. 


\section{Desenlace y seguimiento}

Posterior a 24 horas de su ingreso presenta dificultad respiratoria, ventilaciones superficiales aun refiriendo esfuerzo para respiración profunda, mascarilla con reservorio manteniendo saturaciones del $90 \%$, sin el aporte desaturación del $70 \%$, con incremento de la frecuencia respiratoria, por lo que se decide protección de la vía aérea ante la evidencia clínica de parálisis de la musculatura para su ventilación. Sin embargo, previo a esta presenta bradicardia y actividad eléctrica sin pulso, y se inicia reanimación cardiopulmonar avanzada; se realizan 10 ciclos, con siete desfibrilaciones por fibrilación ventricular persistente, y se administran epinefrina intravenosa en seis ocasiones, bicarbonato y amiodarona. Se mantiene en los tres últimos ciclos en asistolia, sin conseguir el retorno a la circulación espontánea pese a la reanimación.

\section{Discusión}

En general, el empiema subdural espinal es poco común; dependiendo la serie, su incidencia puede ser de 2-25/100.000 a $1 / 10.000^{1}$, con una edad media de aparición de aproximadamente 50 años, con picos a los 50 y 70 años, aunque puede ocurrir a cualquier edad, con una incidencia mayor en los hombres ${ }^{4}$. Entre los factores predisponentes se encuentran que pueden dar lugar a bacteriemia, como uso de drogas inyectables, abscesos dentales, catéteres epidurales, endocarditis infecciosa, intervenciones espinales, alcoholismo, diabetes mellitus, infección por virus de la inmunodeficiencia humana, traumatismos, tatuajes, acupuntura e infección contigua de tejidos blandos $u$ óseos ${ }^{4-6}$.

Las bacterias pueden acceder al espacio epidural por vía hematógena, por extensión directa de tejido contiguo infectado (como un cuerpo vertebral o el músculo psoas) o por inoculación directa en el conducto raquídeo. Aproximadamente un tercio de los pacientes no tienen una fuente identificable de la infección, pero los sitios de origen más comunes son las infecciones de la piel y de los tejidos blandos, y las complicaciones de la cirugía de columna u otros procedimientos invasivos, incluidos los catéteres epidurales que se dejan colocados, generalmente para control del dolor ${ }^{4-6}$.

Las manifestaciones iniciales a menudo son inespecíficas e incluyen fiebre y malestar general. La tríada diagnóstica clásica consiste en fiebre, dolor de espalda y déficit neurológico; sin embargo, solo una pequeña proporción de pacientes tiene los tres componentes en el momento de la presentación ${ }^{6,7}$, siendo el dolor de espalda el síntoma más común. El absceso no tratado puede resultar en una progresión típica de los síntomas neurológicos con el tiempo en cuatro etapas clínicas que se presentan de manera consecutiva ${ }^{7,8}$ :

- Dolor de espalda, que a menudo es focal e intenso.

- Dolor radicular, descrito como «disparos» 0 «descargas eléctricas» en la distribución de la raíz nerviosa afectada.

- Disfunción medular caracterizada por debilidad motora, cambios sensoriales y disfunción de esfínteres.

- Parálisis.

Una vez desarrollada la parálisis, rápidamente puede volverse irreversible. Por lo tanto, puede ser necesaria una intervención urgente si se detecta la progresión de la debilidad $u$ otros hallazgos neurológicos.

El diagnóstico se basa en la sospecha clínica. La punción lumbar está proscrita si la sospecha es alta, dado que puede conllevar el riesgo de diseminación bacteriana al espacio subaracnoideo, con meningitis subsecuente. Se deben realizar imágenes de la columna en todos los pacientes con sospecha clínica, pues la identificación de una colección epidural compatible con un absceso es suficiente para hacer el diagnóstico presuntivo. La resonancia magnética con contraste (gadolinio) es la prueba de imagen preferida porque a menudo es positiva al inicio de la infección y proporciona la mejor visualización de la ubicación y la extensión de los cambios inflamatorios. ${ }^{8}$

Los abscesos visualizados por resonancia magnética suelen mostrar una intensidad de señal equivalente a líquido en las imágenes ponderadas en T2, con realce del borde y un centro hipointenso; algunos se asocian con realce en forma de anillo o realce dural lineal. Si no se puede utilizar gadolinio, la presencia de edema paraespinal y de médula ósea es el hallazgo más frecuente en estos pacientes ${ }^{9,10}$.

Los principios de la terapia óptima son la reducción de tamaño y la eliminación final de la masa inflamatoria y la erradicación del microorganismo causante, lo cual generalmente se logran mediante descompresión quirúrgica y drenaje, junto con terapia antibiótica sistémica. La cirugía debe realizarse lo antes posible y dentro de las 24-36 horas posteriores al inicio de la parálisis ${ }^{5}$. La antibioticoterapia empírica debe elegirse a base de antibióticos activos contra estafilococos (incluido Staphylococcus aureus resistente a la meticilina), estreptococos y bacilos gramnegativos, como por ejemplo ceftriaxona y vancomicina. 


\section{Pronóstico}

Se ha informado una tasa de fracaso del $41 \%$ en pacientes tratados médicamente de inicio. La diabetes, la proteína $C$ reactiva $>115 \mathrm{mg} / \mathrm{l}$, los glóbulos blancos $>12.500 \mathrm{cel} / \mathrm{l}$ y la bacteriemia son factores predictivos de fracaso del tratamiento médico, el cual se define como una disminución del estado motor documentada por un médico mientras se administran antibióticos por vía intravenosa ${ }^{11}$.

\section{Perspectivas del paciente}

Es importante, ante un cuadro de síndrome medular asociado a clínica infecciosa, tener en consideración el diagnóstico de empiema subdural espinal. El paciente tuvo una evolución tórpida y no fue posible un manejo definitivo.

\section{Financiamiento}

La presente investigación no ha recibido ninguna beca específica de agencias de los sectores públicos, comercial o sin ánimo de lucro.

\section{Conflicto de intereses}

Los autores declaran no tener conflictos de intereses.

\section{Responsabilidades éticas}

Protección de personas y animales. Los autores declaran que para esta investigación no se han realizado experimentos en seres humanos ni en animales.

Confidencialidad de los datos. Los autores declaran que han seguido los protocolos de su centro de trabajo sobre la publicación de datos de pacientes.

Derecho a la privacidad y consentimiento informado. Los autores han obtenido el consentimiento informado de los pacientes y/o sujetos referidos en el artículo. Este documento obra en poder del autor de correspondencia.

\section{Bibliografía}

1. Pilkington SA, Jackson SA, Gillett GR. Spinal epidural empyema. $\mathrm{Br} \mathrm{J}$ Neurosurg. 2003;17:196-200

2. Chima-Melton C, Pearl M, Scheiner M. Diagnosis of spinal epidural abscess: a case report and literature review. Spinal Cord Ser Cases. 2017;3:17013.

3. Lener S, Hartmann S, Barbagallo GMV, Certo F, Thomé C, Tschugg A. Management of spinal infection: a review of the literature. Acta Neurochir (Wien). 2018;160:487-96.

4. Sendi P, Bregenzer T, Zimmerli W. Spinal epidural abscess in clinical practice. QJM. 2008;101:1.

5. Darouiche RO. Spinal epidural abscess. N Engl J Med. 2006;355:2012.

6. Krishnamohan P, Berger JR. Spinal epidural abscess. Curr Infect Dis Rep. 2014;16:436.

7. Davis DP, Wold RM, Patel RJ, Tran AJ, Tokhi RN, Chan TC, et al. The clinical presentation and impact of diagnostic delays on emergency department patients with spinal epidural abscess. J Emerg Med. 2004;26:285.

8. Curry WT Jr, Hoh BL, Amin-Hanjani S, Eskandar EN. Spinal epidural abscess: clinical presentation, management, and outcome. Surg Neurol. 2005;63:364.

9. Darouiche RO, Hamill RJ, Greenberg SB, Weathers SW, Musher DM. Bacterial spinal epidural abscess. Review of 43 cases and literature survey. Medicine (Baltimore). 1992;71:369-85.

10. Shifrin A, Lu Q, Lev MH, Meehan TM, Hu R. Paraspinal edema is the most sensitive feature of lumbar spinal epidural abscess on unenhanced MRI. AJR Am J Roentgenol. 2017;209:176-81.

11. Patel AR, Alton TB, Bransford RJ, Lee MJ, Bellabarba CB, Chapman JR. Spinal epidural abscesses: risk factors, medical versus surgical management, a retrospective review of 128 cases. Spine J 2014;14:326-30. 